\title{
STRATEGIES TO ENCOURAGE FEMALES BEGINNING IN MIDDLE SCHOOL AND HIGH SCHOOL TO PARTICIPATE IN THE COMPUTING FIELD
}

\author{
Sushma Mishra, Robert Morris University, mishra@rmu.edu \\ Linda Kavanaugh, Robert Morris University, kavanaugh@rmu.edu \\ Donna L. Cellante, Robert Morris University, cellante@rmu.edu
}

\begin{abstract}
The current reality of IT skills shortages in general and the lack of women in computing has been a subject of interest in the United States in the last decade. We need to better understand the educational environment, especially at the middle school and the high school level, in order to generate interest about technology related preferences, habits, and interests. The purpose of this paper is to recommend strategies for educators to motivate and recruit more women in computing related courses and degrees and into computing careers. This study used focus group methodology for data collection purposes. There are financial/budgetary issues that are preventing high school administrators to be more aggressive in teaching technology courses, social or cultural issues about the perception of the computing field being more male centric, and what information technology is and what scope it has for women entering the field. Proactive strategies are required to encourage the participation of females in computing related courses.
\end{abstract}

Keywords: women in computing, information technologies, high school, middle school, teachers, recruiting, and strategies

\section{INTRODUCTION}

Information Systems (IS) and other computing related fields have witnessed declining enrollments, especially for females, over the years [19]. Computing related jobs are on the rise and the number of women filling these positions is dwindling and this is a disturbing situation with long term socio-cultural and economic implications. This raises new concerns among employers and policy makers as these trends also play out among the ranks of information systems professionals. The current reality of IT skills shortage in general and lack of women in computing in particular has been a subject of interest in the United States in the last decade. As a result, in 2000, the Information Technology Workforce Program (ITWF) was established by the National Science Foundation (NSF) to support research studies on the under-representation of women and minorities in IT [8].

The lack of women in computing has always been a topic of concern to the female faculty in our Computer and Information Systems (CIS) department. The number of women entering computer science and information technology fields is dramatically lower than males. "Is it due to the fact that computing is often considered too technical or is it because girls do not like the symbolic image of the computer geek and believe that a subject such as Computer Science tends to desocialize and isolate the people dealing with it from the rest of the world (Women in Computer Science)?" "Women are definitely still a minority in the tech sector," says Liz Morgan, a talent strategist at Microsoft [15]. "We need to do a better job of prepping women for today's job market," says Cathi Rodgveller, founder of Inspiring Girls Now in Technology Evolution (IGNITE) [15]. Technology jobs are predicted to grow at a faster rate than all other jobs in the professional sector, up to 22 percent over the next decade, according to the Bureau of Labor Statistics. Labor trends show that 1.4 million computer-related jobs will be added in the U.S. by 2018, according to the U.S. Department of Labor and the Bureau of Labor Statistics [17].

A better understanding of perception of today's students about computing would help in restructuring pedagogy and curricula in order to attract more women in this field. We need to better understand the educational environment, especially at the middle school and the high school level, in order to generate interest in boys and girls about technology related preferences, habits and interests [19]. The purpose of this paper is to recommend strategies for educators to motivate and recruit more women in computing related courses and degrees and henceforth into computing careers. The research questions that this study addresses are:

RQ1: What specific things have you done at your school district to recruit females into the IT field? 


\section{Issues in Information Systems}

Volume 14, Issue 1, pp.251-259, 2013

RQ2: What can we do as educators at the middle and high school level to get females involved in technology?

The rest of this paper is organized as follows. The next section presents an analysis of extant research literature in the area of women in computing. The section following the literature review presents the methodology used for this study including data collection and data analysis. The discussions from the findings from our data are presented in section four followed by the conclusions for this study.

\section{LITERATURE REVIEW}

There have been several studies in information systems suggesting a general lack of interest and the under representation of women in science, technology, engineering and math (STEM) disciplines, especially in information technology in United States [5]. We are aware of the declining enrollment trend for women in computing related degrees such as information technology, computer science and information systems. For example, at Robert Morris University, the decline of female IS majors from the period of 1990-2000 is significantly lower than the number from 2001 to 2010. Even though there is an upward trend now, it is not quite at the same level as what we had previously. There have been several studies in this area to understand the underlying social and cultural dynamics behind this. Some researchers believe that there are cultural barriers for women in computing field. Leidner and Kayworth (2006) presented a review of 82 research studies of the organizational and cross-cultural IT literature that links culture with IT. The authors propose that culture in general is a critical variable in explaining how social groups interact with IT and that there is a gap in the literature in defining the values, attitudes and enculturation in IT [11].

It is argued that computing is a male dominated field profession and women face challenges that are unique to them based on their gender. There are many studies about how girls and boys learn differently, or respond to teaching styles differently, or are treated differently in the classroom [19]. Some studies suggest that boys are more confident and behave more proactively in technology classes, while girls are more likely to watch passively. Swanson and Miller (1998) noted that parents were twice as likely to purchase technology for sons over daughters. Strategies to reach out to girls need to address the social and educational environment and aim to reduce gender differences in overall technology self-confidence [4].

McInerney and DiDonato (2008) conducted focus group interviews of information technology students and found that the major influences in choosing a computing major were positive experiences in high school, an aptitude for math, perceived job prestige, encouragement of family members and key teacher input. Students did not have the negative stereotypes and attitudes toward the field. Early intervention is critical to reversing the decline of women in technology careers [13]. Research in this area consistently suggests that lack of K-12 computing courses at middle and high school level, lack of accurate career information about computing related careers and absence of female mentors in the field all play a role in inadvertently turning young women away from the industry [13],[19]. Role mentoring is also considered important for a female to choose a career in IT. A female student enrolled in a computing degree is greatly influenced by her reliance on strong interactions with female high school computer teachers/role models for female students [1].

There are studies that suggest women view a career in computing as a "nerdy" choice. Women feel that there is not enough room for socialization in this career and it is heavily mathematics dominated and hence shy away from it. Freeman (2010) argues that female college students feel a lack of confidence with computer skills because they had learned less and practiced less with computers than male students, thus becoming more anxious and distanced when using computer technology. Good IT students need basic analytical skills and concentrated interests in science, technology and math, and computer technology encompassing the K-12 level is a necessary component [1]. Caputo and Kohun (2002) suggest that curricular innovation was the key element in increasing the enrollment and retention of female students in Computer Information Systems studies. It stemmed from the female student's perception of anxiety when confronted with computer technology, particularly in the area of computer programming. Similarly, Shade (2010), in his/her study with female CIS majors, suggest strategies for improving the representation of women in all aspects of the IT realm. According to these authors, the major factors in the ultimate perception of the 


\section{Issues in Information Systems \\ Volume 14, Issue 1, pp.251-259, 2013}

field were better recruiting and retention strategies, the development of mentors, and changes in the presentation of the information-based body of studies.

Caputo (2010) studied the differences between male and female university students in the Computer Information Systems major as to the perceived value of the importance of technological skills necessary for job success in the prescribed discipline, and the acceptance of those criteria by the female student. Along similar lines, Guthrie (2009) argues that the success of women in the IT industry revolves around the critical support areas of mentoring women in the collegiate IT environment.

A critical review of the research literature in the domain of women in computing reveals an urgent need for getting female students interested in computing curriculum and henceforth in computing careers early on in their educational experiences. This study is addressing this gap by identifying strategies for recruiting and retaining female students in computing related fields at middle and high school level.

\section{RESEARCH METHODOLOGY}

\section{Methodology}

This study used focus group methodology for data collection purposes. In order to gather information about attracting and retaining women in IT, we conducted a focused discussion group with the participants in a session entitled "Women in Computing" at a one-day workshop with high school business, mathematics and technology teachers along with the counselors. The CIS department in this medium size, private, non-profit university, has 22 full-time faculty, of which seven are female. A focus group is a special type of group in terms of purpose, size, composition, and procedures. The purpose of conducting a focus group is to listen and gather information. It is a way to better understand how people feel or think about an issue, product or service [10]. The first 30 minutes of the session was devoted to determining the current perception of secondary educators about women in IT/computing.

The intent of the focus group is to promote self-disclosure among participants. We wanted to know what the teachers and guidance counselors really thought and believed about women in IT. People will self-disclose when they feel comfortable and when the environment is permissive and nonjudgmental. It may be that the participants have one or more characteristics in common. According to Krueger \& Casey (2009)

Focus groups interviewees typically have five characteristics or features: (1) people, who (2) possess certain characteristics, (3) provide qualitative data (4) in a focused discussion (5) to help understand the topic of interest. (p. 6)

The researchers selected the focus group methodology because it has proven to be useful in understanding how or why people hold certain beliefs about a topic. The focus group can provide information on how groups of people think or feel about a particular topic; give insight into why certain opinions are held; and produce insights for developing strategies for outreach. The focus group provides data more quickly and at lower cost than if individuals were interviewed separately; the researcher can interact directly with respondents; the researcher can obtain deeper levels of meaning; and the results are easy to understand.

There are disadvantages to using focus groups as well. The researcher has less control over what information will actually be produced; data analysis is more difficult; and the sample can limit the ability to generalize to a larger population.

\section{Data Collection}

The one-day workshop was co-sponsored by the CIS Department, IBM, and Cengage Learning. It is an annual workshop geared to keeping local teachers current in the field of computing/technology. This year's workshop was entitled "Computing in 2013: What's New?" The focus of the conference was to develop awareness in the shortages businesses will face in the near future because there will not be enough trained people to perform the IT duties. 


\section{Issues in Information Systems \\ Volume 14, Issue 1, pp.251-259, 2013}

We invited business educators, math educators, and guidance counselors from about 130 school districts to the workshop. There were a total of 88 participants who attended the workshop. The participants were selected because they have a certain characteristic in common that relate to the topic; in this case, educators who either teach or guide students about computing. There were 56 business educators, 7 math educators, and 7 guidance counselors, for a total of 70 teachers. There were also 18 presenters including faculty in the audience.

Our goal was to find out from business educators, math educators, and guidance counselors from the high school and middle school level their perceptions about women in computing. Even though we had two main questions that we needed to ask, we added more questions in our session to generate a discussion around the topic. We asked six discussion questions of the participants. The questions were as follows:

(1) What jobs come to mind when you think of the IT field?

(2) How would you define Information Technology/Computing?

(3) Do you believe there is a difference between what boys and girls think about technology?

(4) Do you believe there are more men than women in the IT field? Why or why not?

(5) What specific things have you done at your school district to recruit females into the IT field?

(6) What can we do as educators at the middle and high school level to get females involved in technology?

The session was recorded (audio) with the permission of the participants. All participants were given the opportunity to respond to each question, as well as to interact conversationally within the group. The focus group session was recorded and transcribed.

\section{Data Analysis}

In response to discussion question 1 , several jobs were reported by the group.

Table 1: Jobs Reported in the IT Field

\begin{tabular}{|l|}
\hline Programmer \\
\hline Technical support \\
\hline Software engineer \\
\hline Database manager \\
\hline Systems Analyst \\
\hline Web developer/designer \\
\hline
\end{tabular}

Network systems analysts and computer software engineers are expected to be two of the top 30 fastest-growing professions, according to the U.S. Department of Labor, Bureau of Labor Statistics, 2009. Also, of the 20 occupations with the highest median earnings for women, five are computing occupations: computer software engineers, computer and information systems managers, computer programmers, computer scientists and systems analysts, and network systems and data communication analysts [17].

These IT jobs can be appealing to women for the following reasons: (1) There is a great deal of variety of social interaction within each type of job; (2) There is career mobility to seek the type of interaction must comfortable for a given personality; (3) There are lots of sites available for employment; and (4) There are flexible work times/schedules [6].

In response to discussion question 2 about defining information technology/computing, the responses were short. The teachers themselves could not really define information technology/computing. How can they be expected to guide students to this major when they were unsure. It was discussed that computing refers to the applications side and information technology refers to selecting the right tools to do the task.

Table 2: Definition of Information Technology/Computing

Using technology for a business application 


\section{Issues in Information Systems}

Volume 14, Issue 1, pp.251-259, 2013

\begin{tabular}{|l|}
\hline Collecting, analyzing, and processing data \\
\hline Computing is the use of application \\
\hline Information technology are the things that make the computer go \\
\hline
\end{tabular}

In response to discussion question 3, there were varying views expressed. In analyzing the views, it was clear that educators see boys and girls definitely as different in the way they think about technology.

Table 3: Differences Between Boys and Girls and Their Thinking About Technology

\begin{tabular}{|l|l|}
\hline \multicolumn{1}{|c|}{ Girls } & \multicolumn{1}{c|}{ Boys } \\
\hline Like to communicate & Like robotics and gaming \\
\hline Don't believe they have a strong background in math & Relate to math \\
\hline See computer as a tool & More detail oriented \\
\hline See the bigger picture & See computer as a toy \\
\hline
\end{tabular}

In response to discussion question 4, the participants do believe that there are more men than women in the IT field. As for why or why not, some real-life examples were shared. For example, if you go into Best Buy, you see more men than women assisting customers. In the school districts, you see very few females in the IT department and even fewer female IT teachers. The stereotype of the isolated cubicle as not allowing people to be social was discussed.

Table 4: Are There More Men Than Women in IT? Why or Why Not?

\begin{tabular}{|l|}
\hline "Geek factor" \\
\hline Computer limits social skills and interactions \\
\hline Women lack confidence about technology \\
\hline Peer culture (not cool) \\
\hline Females don't see that as very exciting \\
\hline Work by yourself-need more social environment \\
\hline
\end{tabular}

Discussion question 5 led to a healthy discussion about what teachers and schools can do to recruit females into the IT field. About $30 \%$ of the school districts in the area offer "college in high school" information technology courses as part of the curricula. High school students are given the opportunity to earn college credit while still attending high school.

Table 5: Recruiting Strategies

IT courses need to be taught in business department rather than math department

New courses need to be developed, such as Cyber Forensics

College credit needs to be offered

Courses offered at honors level (senior recognition)

Industry certifications need to offered

Discussion question 6 was asked to determine what educators at both the middle school and high school levels can do to get females involved in technology. Many of the educators expressed that in order for substantial changes to be made, administrators must lead the way.

Table 6: What Can We Do Get Females Involved in Technology?

Get administrators to recognize the importance of technology and make technology a priority for the district

Provide actual hands-on experiences (projects) Introduce programming at earlier age $\left(8^{\text {th }}\right.$ grade $)$

Make course content more relevant (relevant assignments such as iTunes database or

American Idol)

Use programming software like Alice (3D environment) 


\section{Issues in Information Systems}

Volume 14, Issue 1, pp.251-259, 2013

Use fashion (interior design, architecture)

Establish FBLA Clubs (competition)

\section{DISCUSSION AND RECOMMENDATIONS}

This study presents the focus group results about the lack of women representation in information technology degrees and careers. The methodology of conducting this study, along with the results, is presented. Recommendations are provided to identify ways to promote females in IT. We recognize that budgets/technology, cultural change, and defining IT are three areas of concern that we will discuss below.

\section{Budgets/Technology}

Contemporary economic and social issues have impacted nearly all content-area programs, including those in business education (where technology courses are usually housed). One of the most visible trends is a shift away from the teaching of technical skills toward a curriculum that emphasizes the academics (English, Math, Science, and Social Studies). The Keystone Exams are end-of-course assessments designed to assess proficiency in Algebra 1, Algebra 2, Geometry, Literature, English Composition, Biology, Chemistry, US History, World History, and Civics and Government. The Keystone Exams are one component of Pennsylvania's new system of high school graduation requirements.

Several recent legislative bills and initiatives such as No Child Left Behind Act (2002) have impacted funding tied to education, perhaps at the expense of spending monies on technology in the middle and high schools. This past year, 14,000 teachers and other school employees have suffered layoffs in school districts throughout the state. State support for classroom education has been cut from $\$ 6.1$ million in the 2010-2011 budget to $\$ 5.5$ million in the current budget, nearly a $10 \%$ decrease in funds.

Curriculum for business education programs has been impacted by a number of recent trends. Business education programs have been reduced or eliminated as a result of declining funding. Because of these trends, business education programs and curriculum are rapidly changing to meet the dynamic needs of education in general.

\section{Cultural Change/Overcoming Stereotypes}

The issue may have to do with cultural norms and the stereotype of who works in IT. We have gender issues that are not yet at the forefront. For example, buying a boy a truck and a girl a doll could have a lasting effect on his/her future career goals. Overcoming the stereotype of the "tech geek" may take a long time. Simply exposing females to hands-on experiences and female role models in technology can begin to change their mindset. Computing related careers are suffering from stereotypes of women fictionalizing them as geeks. Success in the industry is framed as being dependent on expertise when it is actually highly gendered [16] and the best way to address the problem is by addressing this culture and reestablishing what computing is.

Vilvovsky et al (2008) in a study to understand the technological comfort of boys and girls at middle school and high school found that both genders assess their technical ability the same at middle school level. But by high school, boys report a higher level of ability than girls and also know more about the computer curriculum in their high school. This suggests that while girls seem to be very comfortable using computers for school work, they are less aware of what courses their school offers them compared to high school boys. This suggests that schools could use innovative methods to reach out to their female students.

Companies are beginning to create outreach programs to expose middle school-age children to science, technology, engineering, and math. It is this early exposure that industry leaders believe will erase gender stereotypes. IBM has initiated a program called "Excite" for girls ages 11 to 13, designed to pique their interest in career fields in which women are sparse [9]. 


\section{Issues in Information Systems \\ Volume 14, Issue 1, pp.251-259, 2013}

\section{Defining Information Technology/Computing}

In our discussion with the focus group, there was confusion about this definition. There is a broad disagreement about the definition of information technology in general in educators, students, businesses and policy makers. This varying conception of information technology surfaced in our discussion and we believe that this has deeper consequences than it appears to have. Our definition and the teachers' and guidance counselors' definition of information technology differed. CIS faculty views information technology as the process of development, installation, and implementation of computer systems and applications. The focus group primarily viewed it as software application only (example: Microsoft Office). The bigger picture of computing was missing.

This myopic perception of the technology field by teachers and guidance counselors inadvertently limits the scope of education and career options of the students who interact with them. There is a plethora of career opportunities in technology field, which could be appealing to young women provided they understand and explore these possibilities. Based on our discussions with the focus group, we propose the following recommendations to educators at various levels (Table 7).

Table 7: Recommendations for Educators

\section{Discussion Questions}

What specific things have you done at your school district to recruit females into the IT field?

What can we do as educators at the middle and high school level to get females involved in technology?

\section{Recommendations}

1. All students can learn about robotics, entrepreneurship, website design, or computer programming. The can be done through early education programs, student clubs, and FBLA chapters.

2. Females can be directed toward a profession in technology by a role model, an effective teacher, a direct personal experience, or a mandatory course or elective in technology.

3. Instructors or guidance counselors can provide personal encouragement to female students interested in technology careers.

1. Educate parents, children, and teachers to encourage girls at a young age to explore IT careers. The stereotype of the isolated cubicle is no more. Civil service and government jobs can be a place to be involved with technology.

2. Secondary schools and higher education need to work together to develop an IT career awareness that has a consistent message for potential students.

3. Higher education can provide role models, job shadowing and/or field experiences for young people.

In summary, there are financial/budgetary issues that are preventing high school administrators to be more aggressive in teaching technology courses. There are social or cultural issues about the perception of the computing field being more male centric and having less opportunities for females. And finally there are definitional issues about the discipline itself, what information technology is, what scope it has for women entering the field. This issues need to be considered and addressed at a broader level to get more girls excited about technology early on and pursue educational and occupational opportunities in this field. This study contributes broadly to the body of knowledge in this area in two ways. First, we recommend practical strategies, which administrators at educational institutions can actively pursue, that emerge from our data. There are not many studies in this area that recommend a list of "action-items" for decision makers in academia to address this problem. Second, this study identifies the social, cultural and economic roots of the problem that we are facing due to lack of participation by women in computing field. This would stem further work in this domain and fuel investigations of the structural problems from multiple perspectives. 


\section{Issues in Information Systems}

Volume 14, Issue 1, pp.251-259, 2013

\section{CONCLUSIONS}

This study clearly suggests that proactive strategies are required to encourage the participation of females in computing related courses. This paper is targeted at the perceptions of secondary educators about women in information technology. Information was gathered from the focus group using the discussion questions. The focus group provided us with some insight into the perceptions of educators about women in IT. It is evident that the teachers and high school counselors identify with the lack of motivation and support structure for females in choosing computing related disciplines and careers. Based on our findings, this study argues that systemic changes in recruiting and retaining females in computing disciplines are required. Our list of recommendations is not complete and further studies in this area are needed.

\section{REFERENCES}

1. Bright, S. (2007). Where Have All the Young Geeks Gone. CIO Magazine Vol. 20, No. 15, May 2007.

2. Caputo, D. and Kohun, F. (2002). Strategies for Enrollment, Retention and Integration of Women in a College Information Systems Major, Proceedings of the International Business and Economics Research Conference, Las Vegas, NV, October, 2002

3. Caputo, D. (2010). Gender Differences in Assessing Essential Business Information Systems Technology Skills, International Journal of Management and Information Systems, Vol. 14, No. 2, $2^{\text {nd }}$ Quarter 2010

4. Dholakia, R.R., N. Dholakia, and N. Kshetri (2003). Gender and Internet Usage. The Internet Encyclopedia, ed. By H. Bidgoli, NY: Wiley

5. Fagnot, Isabelle; Guzman, Indira; and Stanton, Jeffrey, "Toward Recruitment And Retention Strategies Based on the Early Exposure to the IT Occupational Culture" (2007). AMCIS 2007 Proceedings. Paper 199.http://aisel.aisnet.org/amcis2007/199

6. Feintuch, H. (2012). The National Center for Women and Information Technology (NCWIT), http://www.insightintodiversity.com/the-national-center-for-women-i... (INSIGHT into Diversity)

7. Freeman, L. and He, J. (2010) Are Men More Technology-Oriented than Women? The Role of Gender on the Development of Computer Self-Efficacy of College Students, Journal of Information Systems Education, Vol. 21, No. 2, 2010

8. Guzman, Indira R.; Sharif, Raed M.; Blanchard, Tyler J.; Ellis, George S.; and Stanton, Jeffrey M., "What Attracts Women to the IT Field? The First Process of Occupational Socialization" (2005). AMCIS 2005 Proceedings. Paper 305. http://aisel.aisnet.org/amcis2005/305

9. IBM's EXCITE program, $\quad$ Retrieved o5/02/13 http://www.technologyiowa.org/en/media/index.cfm?action=display\&newsID $=8702$

10. Krueger, R.A. \& Casey, M.A. (2009). Focus Groups: A Practical Guide for Applied Research (4 ${ }^{\text {th }}$ ed.), Sage Publications, Inc.: Los Angeles

11. Leidner, D. E., \& Kayworth, T. (2006). A Review of Culture in Information Systems Research: Towards a Theory of ITCulture Conflict. MIS Quarterly, 30(2), 357-399.

12. McInerney, C. and DiDonato,N. (2008). Student's Choice of Information Technology Majors and Careers: A Qualitative Study, Information Technology Learning and Performance Journal, Vol. 24, No. 2, 2008

13. Schiavone, K. (2012). Technical difficulties: Lack of women in computer science starts from an early age, $8^{\text {th }}$ August, 2012, Chicago Tribune, retrieved on 04/29/13 http://articles.chicagotribune.com/2012-0808/classified/chi-technical-difficulties-lack-of-women-in-computer-science-starts-from-an-early-age201208081 technology-careers-computer-young-women

14. Swanson, J., E. Miller (1998). Technology: Are We Helping Our Daughters?, Technology Directions, 57(9).

15. Tech jobs abound, but women still outnumbered in the field by Katie Ormsby (blog March 9, 2012) http://blog.newjobs.com/careercenter/tech_jobs_abound_but_women_s... 


\section{Issues in Information Systems}

Volume 14, Issue 1, pp.251-259, 2013

16. Ura, A. (2012). Assistant professor explores lack of women in computer sciences, March $6^{\text {th }}$, 2012, The Daily Texan, Retrieved on 02/29/13 http://www.dailytexanonline.com/news/2012/03/06/assistantprofessor-explores-lack-of-women-in-computer-sciences

17. U.S. Department of Labor, Bureau of Labor Statistics, November 2009

18. U.S. Department of Labor, 2012

19. Vilvovsky, Sonia, Fedorowicz, Jane, and Golibersuch, Andrew J., (2008), Teenagers' Elective Use of Computer Technology in Middle and High Schools: The Role of Gender, (2008), AMCIS 2008 Proceedings. Paper 184http://aisel.aisnet.org/amcis2008/184

20. Why are there so few women in computer science? Women in Computer Science http://cssubg.org/WomenInCS/current_statistics.php 